\title{
ASPECTOS BIOLÓGICOS E NUTRICIONAIS DE Anticarsia gemmatalis Hüb. (LEPIDOPTERA: NOCTUIDAE) EM DIVERSOS GENÓTIPOS DE SOJA
}

Lenita J. Oliveira ${ }^{1}$, Clara B. Hoffmann-Campo ${ }^{1}$ e Regina M. Mazzarin ${ }^{1}$

\section{ABSTRACT}

Biological and Nutritional Aspects of Anticarsia gemmatalis Hüb.

(Lepidoptera: Noctuidae) on Soybean Genotypes.

The effects of seven soybean genotypes ('Tracy', 'IAC-100', IAC-74-2832, BR 79-15149, BR 80-25896, BR 82-12547 and 'Davis') on the biology and quantitative nutrition of Anticarsia gem matalis Hüb. were evaluated in the laboratory. Insect performance on all genotypes was similar, except for 'IAC-100' which was less suitable. On 'IAC-100' larval showed an increase in time of development, a decrease in weight, and lowest values for relative growth rate (RGR), efficiency of conversion of ingested food (ECI) and efficiency of conversion of digested food (ECD).

KEY WORDS: Insecta, resistance, Glycine max, velvetbean caterpillar, nutritional ecology.

\section{RESUMO}

Estudou-se a influência de sete genótipos de soja ('Tracy', 'IAC-100', IAC74-2832, BR 79-15149, BR 80-25896, BR 82-12547 e 'Davis') sobre a biologia e a nutrição quantitativa de Anticarsia gem matalis Hüb. em laboratório. $\mathrm{O}$ desempenho do inseto foi semelhante em todos os genótipos, exceto em 'IAC100 ' onde observou-se um alongamento da fase larval e menor ganho de peso. A taxa de crescimento relativo (RGR), a eficiência de conversão do alimento ingerido (ECI) e digerido (ECD), foram significativamente menores em 'IAC-100' que nos demais genótipos.

PALAVRAS-CHAVE: Insecta, resistência, Glycine max, lagarta-da-soja, ecologia nutricional. 


\section{INTRODUÇÃO}

O manejo de pragas através do uso de variedades resistentes é desejável, não só por representar um custo zero para o agricultor, como por ser compatível com outros métodos de controle utilizados em esquemas de manejo de pragas. Vários programas de resistência de soja a insetos, são direcionados para o melhoramento de linhagens visando resistência a noctuídeos desfolhadores (Sullivan 1985). A resistência a insetos pode ser expressa em termos de impactos sobre elementos-chave do desenvolvimento biológico e da dinâmica populacional. Os aspectos comumente estudados incluem viabilidade e duração e peso dos diversos estádios de desenvolvimento. O objetivo deste trabalho foi testar diversos genótipos de soja, como subsídio para seleção de fontes de resistência a esse inseto, através do estudo de aspectos biológicos e nutricionais de Anticarsia gem matalis Hüb., principal praga desfolhadora da soja.

\section{MATERIAL E MÉTODOS}

Foram realizados dois ensaios em laboratório, com delineamento experimental inteiramente casualizado, com 40 e 20 repetições, respectivamente. Foram testados sete genótipos de soja ('Tracy', 'IAC 100', IAC 74-2832, BR 79-15149, BR 80-25896, BR 82-12547 e 'Davis' como padrão de suscetilidade) sobre o desenvolvimento e nutrição quantitativa de $A$. gemmatalis. Lagartas recém-eclodidas provenientes de criação em meio artificial, foram individualizadas em placas de Petri, contendo discos de aproximadamente $7 \mathrm{~cm}^{2}$ de folíolos de soja (de plantas com três folhas trifoliadas). Os insetos foram observados diariamente até a emergência dos adultos. As lagartas foram pesadas no dia inicial e no dia do máximo desenvolvimento, e as pupas 24 horas após sua formação.

O consumo e a utilização do alimento foram avaliadas no primeiro ensaio a partir do peso de matéria seca do alimento, lagarta e fezes. Os índices nutricionais $(\mathrm{RCR}=$ taxa relativa de consumo, $\mathrm{RMR}=$ taxa metabólica relativa, $\mathrm{RGR}=$ taxa de crescimento relativo, $\mathrm{ECI}$ = eficiência de conversão do alimento digerido, $\mathrm{AD}=$ digestibilidade aproximada) foram calculados para a fase larval completa (Waldbauer 1968, Scriber \& Slansky 1981). Na determinação da quantidade de alimento oferecido foram utilizadas, cinco placas de Petri/tratamento sem lagartas (testemunha), contendo o mesmo número de discos oferecido às lagartas no período de consumo. Os discostestemunha, as sobras de alimento e as fezes, armazenados em recipientes individuais até o fim do período de consumo, foram secos em estufa e pesados. O peso seco das lagartas foi determinado em criação paralela, cujos espécimes foram pesados no máximo desenvolvimento, mortos por congelamento e secos em estufa e novamente pesados. A partir desses dados foi obtido um fator de correção para peso constante das lagartas (Soo Hoo \& Fraenkel 1966). No segundo ensaio, foram avaliados o ganho de peso e o consumo foliar para o quarto ínstar, exceto para 'Tracy'. Três lotes de quinze casais de $A$. gemmatalis criados em cada genótipo foram colocados em gaiolas individuais e observados diariamente, anotando-se o número de ovos e a mortalidade. A partir dessas observações, foi elaborada uma tabela de vida de fertilidade (Silveria Neto et al. 1976). Os dados obtidos foram submetidos a análise de variância e as médias comparadas pelo teste de Tukey, ao nível de $5 \%$. 


\section{RESULTADOS E DISCUSSÃO}

Em todos os genótipos o ciclo do inseto foi semelhante ao observado na cultivar padrão 'Davis', com exceção de 'IAC 100', na qual a fase larval foi significativamente mais longa (Tabela 1) e o peso máximo atingido pelas lagartas foi o menor (Tabela 2).

Tabela 1. Desenvolvimento de Anticarsia gemmatalis em diversos genótipos de soja.

\begin{tabular}{llll}
\hline & \multicolumn{3}{c}{ Duração da fase (dias) } \\
\cline { 2 - 4 } Genótipo & Larval & Pupal & Ovo-Adulto \\
\hline IAC-100 & $13,48 \mathrm{a}(82)^{2}$ & $9,45 \mathrm{ab}(98)$ & $22,59 \mathrm{ab}(81)$ \\
BR 82-12547 & $13,09 \mathrm{ab}(73)$ & $9,60 \mathrm{ab}(95)$ & $23,18 \mathrm{a} \mathrm{(70)}$ \\
IAC-74-2832 & $13,03 \mathrm{ab}(75)$ & $9,76 \mathrm{ab}(92)$ & $22,85 \mathrm{ab}(70)$ \\
Tracy & $13,00 \mathrm{ab}(82)$ & $9,35 \mathrm{~b}(98)$ & $22,50 \mathrm{~b}(81)$ \\
BR 80-25896 & $12,85 \mathrm{~b}(81)$ & $9,90 \mathrm{a}(94)$ & $23,07 \mathrm{ab}(76)$ \\
Davis & $12,79 \mathrm{~b}(88)$ & $9,57 \mathrm{ab}(91)$ & $22,62 \mathrm{ab}(81)$ \\
BR 79-15149 & $12,64 \mathrm{~b}(87)$ & $9,68 \mathrm{ab} \mathrm{(97)}$ & $22,59 \mathrm{ab}(85)$ \\
\hline CV\% & 5,67 & 8,62 & 4,59 \\
\hline
\end{tabular}

${ }^{1}$ Médias seguidas pela mesma letra não diferem significativamente entre si ao nível de 5\% pelo teste de Tukey (análise conjunta de dois ensaios). ${ }^{2} \mathrm{Os}$ valores entre parênteses indicam viabilidade.

A quantidade de folhas (matéria seca) ingerida pelas lagartas, durante a fase larval completa, foi semelhante em todos os genótipos. Entretanto, a taxa de consumo relativo (RCR) foi maior para 'IAC 100' (Tabela 3).

Tabela 2. Consumo foliar, peso larval no máximo desenvolvimento e peso de pupa ( $24 \mathrm{~h})$ de Anticarsiagemmatalis alimentando-se de vários genótipos de soja.

\begin{tabular}{llll}
\hline Genótipo & \multicolumn{2}{c}{ Peso seco $(\mathrm{mg})$} & $\begin{array}{l}\text { Peso fresco } \\
\text { (mg) } \\
\text { pupa }\end{array}$ \\
\cline { 2 - 3 } & $\begin{array}{l}\text { Folha } \\
\text { ingerida }\end{array}$ & Lagarta & \\
\hline Tracy & 305,86 n.s. $^{1}$ & $69,22 \mathrm{a}^{2}$ & 225,11 n.s. \\
IAC 74-2832 & 280,57 & $67,48 \mathrm{a}$ & 213,36 \\
BR 82-12547 & 301,83 & $66,92 \mathrm{a}$ & 226,06 \\
Davis & 290,07 & $66,74 \mathrm{a}$ & 208,28 \\
BR 79-15149 & 284,25 & $66,79 \mathrm{a}$ & 209,37 \\
BR 80-25896 & 290,59 & $64,76 \mathrm{a}$ & 218,25 \\
IAC 100 & 287,57 & $54,01 \mathrm{~b}$ & 215,79 \\
\hline C.V.\% & 11,25 & 9,77 & 14,10 \\
\hline
\end{tabular}

${ }^{1}$ Médias não diferem significativamente entre si pelo teste de $\mathrm{F}$ a $5 \%$. ${ }^{2}$ Médias seguidas pela mesma letra não diferem significativamente entre si ao nivel de $5 \%$ pelo teste de Tukey. 
A taxa de crescimento relativo (RGR) foi significativamente menor para 'IAC 100' em relação ao obtido na cultivar Davis, o mesmo ocorrendo com a eficiência de conversão de alimento ingerido (ECI) e digerido (ECD). A digestibilidade aproximada (AD) e a taxa metabólica relativa (RMR), não diferiram entre os genótipos e o padrão ('Davis') (Tabela 3).

Tabela 3. Índices nutricionais para a fase larval completa de Anticarsia gemmatalis alimentando-se em vários genótipos de soja.

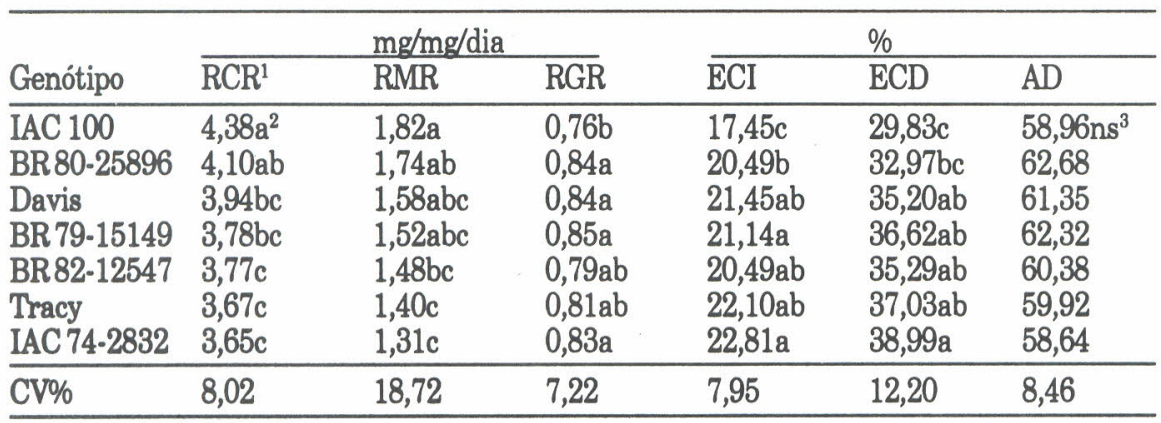

'RCR: taxa relativa de consumo; RMR = taxa metabólica relativa; RGR = taxa de crescimento relativo; ECI = eficiência de conversão do alimento digerido; $\mathrm{AD}=$ digestibilidade aproximada.

${ }^{2}$ Médias seguidas pela mesma letra não diferem significativamente entre si ao nivel de $5 \%$ pelo teste de Tukey.

${ }^{3}$ Médias não diferem significativamente entre si pelo teste de $\mathrm{F}$ a $5 \%$.

O consumo foliar (peso seco) no $4^{\circ}$ instar foi maior para BR 79-15149 e BR 82-12547; para outros genótipos não houve diferença da 'Davis'. O ganho de peso larval, durante esse instar, também foi menor para 'IAC 100' em relação ao padrão (Tabela 4). Em relação ao desempenho reprodutivo, não houve diferenças significativas entre os genótipos (Tabela 5).

Tabela 4. Ganho de peso e consumo foliar durante o quarto ínstar larval de Anticarsia gemmatalis alimentando-se em vários genótipos de soja.

\begin{tabular}{lll}
\hline Genótipos & $\begin{array}{l}\text { Ganho de peso fresco } \\
\text { lagarta } \\
(\mathrm{mg})\end{array}$ & $\begin{array}{l}\text { Peso seco de } \\
\text { folha ingerida } \\
\text { (mg) }\end{array}$ \\
\hline Davis & $92,91 \mathrm{a}^{1}$ & $30,88 \mathrm{~cd}$ \\
BR 79-15149 & $92,28 \mathrm{a}$ & $37,15 \mathrm{~b}$ \\
BR 80-25896 & $88,80 \mathrm{ab}$ & $30,59 \mathrm{~cd}$ \\
BR 82-12547 & $87,90 \mathrm{ab}$ & $41,23 \mathrm{a}$ \\
IAC 74-2832 & $86,45 \mathrm{ab}$ & $32,90 \mathrm{c}$ \\
IAC 100 & $79,83 \mathrm{~b}$ & $26,65 \mathrm{~d}$ \\
\hline CV\% & 20,82 & 26,59 \\
\hline
\end{tabular}

${ }^{1}$ Médias seguidas pela mesma letra não diferem significativamente entre si pelo teste de Tukey a $5 \%$. 
Lustosa et al. (1989), em estudos de preferência alimentar de $A$. gem matalis utilizando 'Davis' como padrão, observaram rejeição da linhagem BR 82-12547; Hoffmann-Campo \& Mandarino (1991) observaram que essa rejeição está possivelmente ligada a um elemento químico. Em confinamento não houve efeitos negativos dessa linhagem no desenvolvimento e na fisiologia nutricional do inseto, e embora o maior consumo foliar no quarto instar possa representar resposta compensatória a um menor consumo inicial, supõe-se que esse aleloquímico tenha efeito mais repelente que deterrente.

Tabela 5. Tabela de vida de fertilidade de Anticarsia gemmatalis em diversos genótipos de soja.

\begin{tabular}{lllll}
\hline Genótipos & $\mathrm{RO}^{1}$ & $\mathrm{~T}$ & $\mathrm{rm}$ & $\lambda$ \\
\hline IAC 100 & 248,67 n.s. $^{2}$ & 32,37 n.s. & 0,1686 n.s. & 1,1837 n.s. \\
Tracy & 284,14 & 32,17 & 0,1755 & 1,1866 \\
BR 80-25896 & 312,62 & 31,55 & 0,1803 & 1,1976 \\
BR 79-15149 & 314,03 & 32,23 & 0,1773 & 1,1941 \\
BR 82-12547 & 320,10 & 32,30 & 0,1765 & 1,1932 \\
Davis & 321,76 & 32,02 & 0,1789 & 1,1959 \\
IAC 74-2832 & 335,22 & 32,28 & 0,1743 & 1,1907 \\
\hline CV\% & 16,71 & 1,52 & 3,10 & 0,54 \\
\hline
\end{tabular}

${ }^{1}$ Taxa líquida de reprodução (RO); duração média de uma geração (T); capacidade de aumentar em número $(\mathrm{rm})$; razão finita de aumento $(\lambda)$ ${ }^{2}$ Médias não diferem significativamente entre si pelo teste de $\mathrm{F}$ a $5 \%$.

Uma análise geral dos resultados mostrou que o genótipo menos adequado para $A$. gemmatalis foi 'IAC 100'. As lagartas criadas nessa cultivar apresentaram um menor aproveitamento do alimento (ECI e ECD), o que resultou em menor peso larval, apesar da maior taxa de consumo diário (RCR). $\mathrm{O}$ alongamento da fase larval pode ter sido uma resposta compensatória para atingir o peso ideal, em função do alimento menos adequado. Essa resposta tem sido observada para $A$. gemmatalis (Beach \& Todd. 1988). A despeito do menor peso atingido pela lagarta, as pupas em 'IAC 100', não mostraram diferenças significativas de peso em relação aos demais genótipos (Tabela 1). Isso sugere que durante a mudança de fase o inseto pode ter aumentado a eficiência de reabsorção da cutícula; a cultivar pode representar mais de $20 \%$ da produção total da biomassa larval (Parra 1991). As alterações observadas não afetaram a capacidade reprodutiva do inseto, mas podem ter algum efeito na viabilidade dos ovos e no desenvolvimento das gerações seguintes (parâmetros que não foram avaliados no presente trabalho). 


\section{AGRADECIMENTOS}

As autoras agradecem a dedicação do técnico de laboratório Antônio Carlos Ferreira Mendes.

\section{LITERATURA CITADA}

Beach, R.M. \&J.W.Todd. 1988. Foliage consumptiom and developmental parameters of the soybean looper and the velvetbean caterpillar (Lepidoptera: Noctuidae) reared on susceptible and resistant soybean genotypes. J. Econ. Entomol. 81:310-316.

Hoffmann-Campo, C.B. \& J.M.G. Mandarino. 1991. Influência dos princípios fitoquímicos da linhagem de soja BR-82-12547 na preferência alimentar de Anticarsia gem matalis (Hübner) (Lep. Noctuidae). In Congresso Brasileiro de Entomologia, 13, Recife, p. 541.

Lustosa, P.R., C.B. Hoffmann-Campo \& R.M. Mazzarin. 1989. Teste de preferência alimentar e ganho de peso de Anticarsia gemmatalis Hübner, 1818 (Lep., Noctuidae) em genótipos de soja com característica de resistência a insetos. In Congresso Brasileiro de Entomologia, 12, Belo Horizonte, p. 382.

Parra, J.R.P. 1991. Consumo e utilização de alimentos por insetos, p. 9-66. In A.R. Panizzi \& J.R.P. Parra (eds.), Ecologia nutricional de insetos e suas implicações no manejo de pragas, São Paulo, Manole, 360p.

Scriber, J.M. \& F. Slansky Júnior. 1981. The nutritional ecology of immature insects. Annu. Rev. Entomol. 26: 183-221.

Silveira Neto, S., O. Nakano, D. Barbin. \& M.A. Villa Nova. 1976. Manual de ecologia de insetos. São Paulo, Ceres, 420p.

Soo Hoo, C.F. \& G. Fraenkel, 1966. The consumption, digestion and utilization of food plants by a polyphagous insect Prodenia eridania (Cramer). J. Ins. Physiol. 12:711-30.

Sullivan, M.J. 1985. Resistance to insect defoliators. p. 400-405. In R. Shibles (ed.), Proceedings World Soybean Research Conference, 3, Boulder, Westview Press, 1262 p.

Waldbauer, G.P. 1968. The consumption and utilization of food by insects. Adv. Ins. Physiol. 5: 229-88. 